\title{
C242T polymorphism of the NADPH oxidase $p 22 P H O X$ gene and its association with endothelial dysfunction in asymptomatic individuals with essential systemic hypertension
}

\author{
ADNAN RAFIQ ${ }^{1}$, KHURSHEED ASLAM $^{3}$, ROUF MALIK ${ }^{3}$ and DIL AFROZE ${ }^{2}$ \\ ${ }^{1}$ Gastroenterology Division, ASCOMS \& Hospital, Jammu, Jammu and Kashmir 190011; Departments of ${ }^{2}$ Immunology \\ and Molecular Medicine, and ${ }^{3}$ Cardiology, Sher-i-Kashmir Institute of Medical Sciences, Srinagar 190011, India
}

Received August 7, 2012; Accepted November 22, 2012

DOI: $10.3892 / \mathrm{mmr} .2014 .1992$

\begin{abstract}
Vascular oxidative stress is an important factor in hypertension-associated vascular damage and is mediated by nicotinamide adenine dinucleotide phosphate (NADPH) oxidase activation. The $\mathrm{C} 242 \mathrm{~T}$ polymorphism at the $p 22 \mathrm{PHOX}$ gene affects binding of $p 22 \mathrm{PHOX}$ to heme, leading to variants of NADPH oxidase that produce different levels of reactive oxygen species (ROS). Specific variations in ROS are associated with an altered risk of developing cardiovascular disease. In the present study, 140 permanent Kashmiri-resident individuals were recruited (75 with essential systemic hypertension and 65 normotensive controls). Endothelial function was assessed non-invasively using high-resolution ultrasonography of the brachial artery. Endothelium-dependent vasoreactivity was expressed in terms of flow-mediated dilation. The TT genotype was identified in $2 \%$ of hypertensive and $7 \%$ of normotensive individuals. Frequency of the T-allele was not observed as significantly different between hypertensive and normotensive individuals $(\mathrm{P}=0.24$; $\mathrm{OR}=0.4 ; 95 \% \mathrm{CI}, 0.07-2.2)$. Blood pressure or the prevalence of hypertension did not vary between C242T $p 22$ PHOX genotypes or in the presence or absence of the T-allele.
\end{abstract}

\section{Introduction}

Endothelial dysfunction was one of the first vascular abnormalities of atherosclerosis to be identified (1). Abnormalities in endothelial function resulting from non-denuding injuries caused to the endothelium by conditions or risk factors that predispose to atherosclerotic cardiovascular $(\mathrm{CV})$ disease may be present prior to development of detectable arterial wall lesions (2-4). Oxidative processes in the vessel wall result in low-grade inflammation with attachment and subsequent migration of

Correspondence to: Dr Dil Afroze, Department of Immunology and Molecular Medicine, Sher-i-Kashmir Institute of Medical Sciences, Srinagar 190011, India

E-mail: afrozedil@gmail.com

Key words: p22PHOX, polymorphism, hypertension, Kashmir monocyte-macrophages, leading to a number of humoral and cellular events characteristic of endothelial dysfunction (5-7). Endothelial dysfunction of risk-factor-exposed or atherosclerotic vessels appears to be a consequence of excessive production of reactive oxygen species (ROS) within the vascular wall $(8,9)$. Moreover, ROS scavenging by superoxide dismutase has been demonstrated to improve coronary endothelial vasodilation (10).

The most important source of superoxide in the vasculature is the membrane-associated enzyme nicotinamide adenine dinucleotide phosphate (NADPH) oxidase $(11,12)$. NADPH oxidase is an important contributor to impaired endothelium-dependant vasodilation in animal $(12)$ and human $(13,14)$ vascular tissue. NADPH oxidase is a multi-subunit enzyme complex comprising p47PHOX, p67PHOX, gp91PHOX, p22PHOX and rac-2 protein. The membrane-bound $p 22 P H O X$ protein, expressed in vascular smooth muscle and endothelial cells, functions as the final electron transporter from NADPH to molecular oxygen and is essential for the assembly and activation of NADPH oxidase (15). Therefore, the expression and activity of this component may be a key determinant of superoxide generation by vascular NADPH oxidase (16). Expression of p22PHOX has been identified at higher levels in human atherosclerotic coronary compared with non-atherosclerotic arteries, indicating that $p 22 \mathrm{PHOX}$ may be involved in the pathophysiology and pathogenesis of atherosclerotic $\mathrm{CV}$ disease (17). Several genetic variations in the $p 22 \mathrm{PHOX}$ gene have been identified, a number of which correlate with $\mathrm{CV}$ diseases (18). The $\mathrm{C} 242 \mathrm{~T}$ variation is a functional single nucleotide polymorphism, located on exon 4 and encodes a non-conservative $\mathrm{C} \rightarrow \mathrm{T}$ replacement that results in the substitution of histidine 72 for tyrosine. By affecting p22PHOX binding to heme, the $\mathrm{C} 242 \mathrm{~T}$ polymorphism may produce variants of NADPH oxidase associated with different levels of ROS production and an altered risk of developing CV diseases $(19,20)$.

Although the pathogenesis of hypertension is complex and multifactorial, a role for increased ROS generation has been hypothesized in a number of studies, particularly with respect to AngII-dependent hypertension (21). For example, vascular NADPH oxidase activity is increased in rats made hypertensive by chronic AngII infusion (12), together with increases in the expression of Nox1, 2 and 4 (22) and p22PHOX mRNA (23).

Vascular oxidative stress is involved in hypertension-associated vascular damage (24-28) and appears to be mediated 
Table I. Cardiovascular risk factor profile in the study population.

\begin{tabular}{|c|c|c|c|}
\hline Risk parameters & Hypertensive (n=75) & Normotensive $(n=65)$ & P-value \\
\hline Smoker, n (\%) & $28(37.33)$ & $2(3.07)$ & $<0.0001$ \\
\hline Increased BMI, n (\%) & $32(42.60)$ & $23(35.38)$ & 0.55 \\
\hline Central obesity $^{\mathrm{a}}, \mathrm{n}(\%)$ & $10(13.33)$ & $8(12.30)$ & 0.86 \\
\hline Dyslipidemia $^{\mathrm{b}}, \mathrm{n}(\%)$ & $63(84.00)$ & $45(69.23)$ & 0.45 \\
\hline High T-C, n (\%) & $27(36.00)$ & $21(32.30)$ & 0.75 \\
\hline High LDL-C, n (\%) & $5(6.66)$ & $8(12.30)$ & 0.30 \\
\hline Low HDL-C, n (\%) & $52(69.33)$ & $28(43.07)$ & 0.09 \\
\hline High TG, n (\%) & $48(64.00)$ & $30(46.14)$ & 0.25 \\
\hline \multicolumn{4}{|l|}{ Framingham risk } \\
\hline Score & $5.778 \pm 4.263$ & $1.371 \pm 4.187$ & $<0.0001$ \\
\hline 10-year CHD risk & $12.98 \pm 9.160$ & $4.740 \pm 3.270$ & $<0.0001$ \\
\hline
\end{tabular}

by NADPH oxidase activation, through rennin-angiotensin system (RAS)-dependent $(12,21)$ and RAS-independent (29) mechanisms. Previous studies demonstrated that an increased expression of $p 22 \mathrm{PHOX}$ is associated with enhanced NADPH oxidase activity in hypertension $(23,30,31)$. Furthermore, elevated NADPH oxidase activity (32) and an increased expression of p22PHOX (33) have been identified to correlate with impaired bioavailability of nitric oxide (NO) in hypertension. Since the $\mathrm{C} 242 \mathrm{~T}$ polymorphism at the $p 22 \mathrm{PHOX}$ gene modulates production of ROS in vasculature by affecting NADPH oxidase enzyme activity $(20,34,35)$, existence of this genetic polymorphism may be an important determinant of vascular dysfunction in patients with essential hypertension. In an additional study, hypertensive individuals carrying the CC genotype of this polymorphism exhibited features of NADPH oxidase-mediated oxidative stress and endothelial damage as indicated by enhanced plasma levels of von-Willebrand factor (36).

Ethnicity is an important determinant of genetic polymorphisms. While distribution of allelic variations in the gene for p22PHOX have been established for several ethnic groups worldwide $(34,35,37-47)$, to date, no studies have been performed on individuals living on the Indian subcontinent. Therefore, the aim of the present study was to analyze the distribution of $\mathrm{p} 22 \mathrm{PHOX}$ C242T genotypes and alleles in a community-based sample drawn from the Kashmiri population. In view of the potential significance of the $p 22 \mathrm{PHOX}$ gene C242T polymorphism for NO bioavailability, the functional relevance of this genetic variation to vascular function is of interest.

\section{Materials and methods}

Patient population. The present cross-sectional study was conducted at the Sher-i-Kashmir Institute of Medical Sciences (Srinagar, India). Local permanent residents were invited to take part in the study. A total of 140 independent, apparently healthy individuals, aged 30-65 years were recruited (75 with essential systemic hypertension and 65 normotensive controls).
The ethics committee of the Sher-i-Kashmir Institute of Medical Sciences approved the study, and written informed consent was obtained from the patient/ the patient's family.

General evaluation. Peripheral venous blood samples for routine laboratory tests were obtained from individuals instructed to fast overnight. Estimated glomerular filtration rate (eGFR) was calculated according to the modification of diet in renal disease formula (48). Plasma lipid parameters were measured using standard enzymatic methods on a fully automatic multichannel chemistry analyzer (Hitachi 912, Roche Diagnostics, Tokyo, Japan). Commercially available kits from Randox Laboratories, Ltd. (Crumblin, UK) were used for estimation of total cholesterol (T-C), triglyceride (TG) and direct low-density lipoprotein-cholesterol (LDL). High-density lipoprotein-cholesterol (HDL) was estimated by the second generation enzymatic assay using a kit obtained from Roche Diagnostics. High-resolution ultrasonography of the brachial artery was performed to determine flow-mediated dilatation (FMD) as a measure of endothelium-dependent vasodilatation.

Genotyping analysis. Total genomic DNA was extracted from whole blood using the phenol-chloroform method. The 353 -bp target region of the p22PHOX gene was amplified by polymerase chain reaction using the following primers: sense 5'-TGCTTGTGGGTAAACCAAGG-3' and antisense 5'-GGAAAAACACTGAGGTAAGTG-3' in a $25-\mu 1$ reaction volume. The reaction consisted of an initial denaturation step of 2 min at $95^{\circ} \mathrm{C}$, followed by 35 cycles of $3 \mathrm{~min}$ at $95^{\circ} \mathrm{C}$ (denaturation), $1 \mathrm{~min}$ at $56^{\circ} \mathrm{C}$ (annealing) and $7 \mathrm{~min}$ at $72^{\circ} \mathrm{C}$ (extension) and a final extension of $7 \mathrm{~min}$ at $72^{\circ} \mathrm{C}$. The 353-bp PCR product was cleaved with $1 \mu \mathrm{l} R s \mathrm{I}$ restriction enzyme for $18-24 \mathrm{~h}$ at $37^{\circ} \mathrm{C}$. Restriction fragments were separated on a $2.5 \%$ agarose gel. Digestion of the amplicon produced a 353-bp band in CC homozygous, 193- and 160-bp bands in TT homozygous and all three bands in CT heterozygous individuals. 
Table II. Genotype frequencies, ORs and CIs of p22PHOX-associated genotypes.

A, Genotype frequencies of the p22PHOX polymorphism in hypertensive and normotensive individuals

\begin{tabular}{llllll}
\hline & & \multicolumn{3}{c}{ Genotype $^{\mathrm{a}}$} & \\
\cline { 3 - 5 } Polymorphism & Variables & $\mathrm{CC}$ & $\mathrm{CT}$ & $\mathrm{TT}$ & Variant allele frequency \\
\hline C242T & Total $(\mathrm{n}=140)$ & 70 & 63 & 7 & 0.275 \\
& Hypertensive $(\mathrm{n}=75)$ & 35 & 38 & 2 & 0.277 \\
& Normotensive $(\mathrm{n}=65)$ & 35 & 25 & 5 & 0.271 \\
\hline
\end{tabular}

B, ORs (95\% CIs) for p22PHOX-associated genotypes

\begin{tabular}{lccc}
\hline Polymorphism & Genotype & $\begin{array}{c}\text { Normotensive vs. } \\
\text { hypertensive, OR (95\% CI) }\end{array}$ & P-value \\
\hline C242T & CC & 1.00 & 0.23 \\
& CT & $1.52(0.76-3.0)$ & 0.24 \\
TT & $0.40(0.07-2.2)$ & 0.39
\end{tabular}

aild-type allele is denoted by $\mathrm{C}$ and the polymorphic allele by T. OR, odds ratio; CI, confidence interval.

Statistical analysis. $\mathrm{P}<0.05$ was used to indicate statistically significant differences.

\section{Results}

$C V$ risk factors. $\mathrm{CV}$ risk factors in the study population are presented in Table I. Greater prevalence of low HDL concentration was observed in hypertensive compared with normotensive individuals. Smoking status was markedly correlated with prevalence of hypertension $(\mathrm{P}<0.0001)$. Overall $\mathrm{CV}$ risk factor score (Framingham score) and the calculated 10-year coronary heart disease (CHD) risk were identified as significantly higher in hypertensive compared with normotensive individuals. A 10 -year CHD risk of $>20 \%$ was calculated in $\sim 1 / 4$ of hypertensive individuals.

p22PHOX gene polymorphisms. The overall study population was in Hardy-Weinberg equilibrium. Half of the individuals were identifed with the CC genotype. The TT homozygous genotype was observed in only $5 \%$ of study participants (Table II).

The clinical and laboratory characteristics of individuals with various $\mathrm{C} 242 \mathrm{~T}$ genotypes are presented in Table III. Anthropometric measurements, blood pressure (BP), serum creatinine and uric acid levels, eGFR and plasma lipid parameters were comparable among the three genotypes. However, individuals with the TT genotype were observed to have significantly lower fasting blood glucose (BG) levels compared with other genotypes. Serum T-C and TGs demonstrated a linear association among the three genotypes.

Correlation between the C242T polymorphism in the p22PHOX gene and brachial artery reactivity. Results of brachial artery reactivity testing are presented in Table IV.

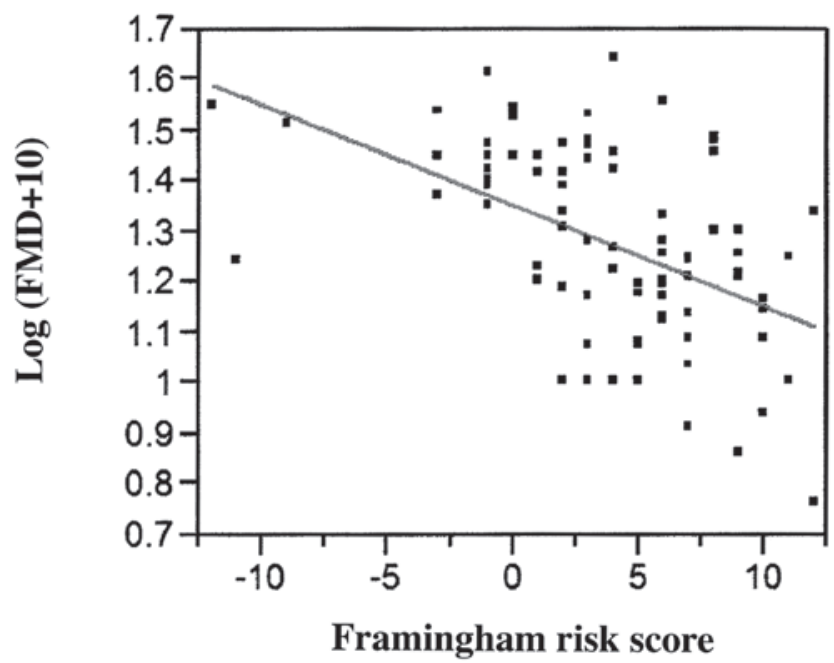

Figure 1. Regression plot presenting the relationship between Framingham risk score and FMD. P<0.0001. FMD, flow-mediated dilation.

Blood flow through the brachial artery prior to occlusion and during the hyperemic phase was comparable between hypertensive and normotensive individuals, as was the degree of reactive hyperemia. Impaired FMD response correlated with endothelial dysfunction (Table V). A higher Framingham risk score was associated with lower FMD (Fig. 1). In the overall population, brachial artery reactivity did not vary across the p22PHOX genotypes. Baseline and hyperemic brachial artery diameter were comparable and no significant difference was detected in \% FMD between the three genotypes. However, on subgroup analysis, FMD was observed to be significantly higher in hypertensive individuals with the T-allele compared with those without the T-allele $(\mathrm{P}=0.046)$. 
Table III. Clinical and laboratory features in individuals with different genotypes.

\begin{tabular}{|c|c|c|c|c|}
\hline \multirow[b]{2}{*}{ Variable } & \multicolumn{3}{|c|}{ Genotype } & \multirow[b]{2}{*}{ P-value } \\
\hline & $\mathrm{CC}(\mathrm{n}=70)$ & $\mathrm{CT}(\mathrm{n}=63)$ & $\mathrm{TT}(\mathrm{n}=7)$ & \\
\hline Age (years) & $45.53 \pm 6.99$ & $45.81 \pm 8.37$ & $49.50 \pm 8.81$ & 0.83 \\
\hline Gender (male) & $53(75.71)$ & $51(80.95)$ & $7(100)$ & 0.87 \\
\hline $\operatorname{BMI}\left(\mathrm{kg} / \mathrm{m}^{2}\right)$ & $24.00 \pm 3.05$ & $24.15 \pm 3.07$ & $24.62 \pm 14.28$ & 0.77 \\
\hline Waist (cm) & $87.25 \pm 9.38$ & $85.28 \pm 9.28$ & $93.00 \pm 29.10$ & 0.22 \\
\hline Smoker & $14(20.00)$ & $16(25.39)$ & $2(28.57)$ & 0.80 \\
\hline Hypertension, n (\%) & $37(52.85)$ & $40(63.49)$ & $2(28.50)$ & 0.26 \\
\hline $\mathrm{SBP}(\mathrm{mmHg})$ & $132 \pm 17$ & $137 \pm 21$ & $128 \pm 13$ & 0.13 \\
\hline DBP (mmHg) & $85 \pm 11$ & $87 \pm 12$ & $85 \pm 10$ & 0.31 \\
\hline $\mathrm{Hb}(\mathrm{gm} / \mathrm{dl})$ & $13.96 \pm 1.62$ & $14.26 \pm 1.90$ & $14.09 \pm 0.95$ & 0.32 \\
\hline $\operatorname{TLC}\left(\times 10^{-9} / 1\right)$ & $6.14 \pm 1.80$ & $5.73 \pm 1.42$ & $5.93 \pm 0.98$ & 0.15 \\
\hline $\operatorname{ESR}(\mathrm{mm} / \mathrm{h})$ & $9.68 \pm 9.06$ & $8.14 \pm 6.34$ & $8.0 \pm 8.12$ & 0.26 \\
\hline $\mathrm{SCr}(\mathrm{mg} / \mathrm{dl})$ & $0.99 \pm 0.20$ & $0.99 \pm 0.21$ & $1.11 \pm 0.49$ & 1.0 \\
\hline eGFR (ml/min) & $84.81 \pm 19.67$ & $85.59 \pm 17.78$ & $91.19 \pm 47.60$ & 0.81 \\
\hline $\mathrm{FBG}(\mathrm{mg} / \mathrm{dl})$ & $91.8 \pm 16.0$ & $83.3 \pm 13.2$ & $77.0 \pm 12.1$ & 0.0012 \\
\hline $\mathrm{UA}(\mathrm{mg} / \mathrm{dl})$ & $6.40 \pm 1.52$ & $6.13 \pm 1.67$ & $5.58 \pm 1.46$ & 0.33 \\
\hline $\mathrm{T}-\mathrm{C}(\mathrm{mg} / \mathrm{dl})$ & $191 \pm 50$ & $172 \pm 32$ & $201 \pm 52$ & 0.01 \\
\hline LDL-C (mg/dl) & $112 \pm 38$ & $105 \pm 35$ & $132 \pm 53$ & 0.27 \\
\hline HDL-C (mg/dl) & $39.4 \pm 8.4$ & $38.0 \pm 10.4$ & $39.5 \pm 10.1$ & 0.40 \\
\hline $\mathrm{TG}(\mathrm{mg} / \mathrm{dl})$ & $191 \pm 98$ & $155 \pm 61$ & $163 \pm 23$ & 0.01 \\
\hline Framingham risk score & $3.70 \pm 4.64$ & $3.83 \pm 5.08$ & $5.50 \pm 2.64$ & 0.87 \\
\hline
\end{tabular}

Figures in parenthesis indicate range in case of continuous variables and the percentage in case of categorical variables. BMI, body mass index; SBP, systolic blood pressure; DBP, diastolic blood pressure; Hb, hemoglobin; TLC, total leukocyte count; ESR, erythrocyte sedimentation rate; $\mathrm{SCr}$, serum creatinine; eGFR, estimated glomerular filtration rate; FBG, fasting blood glucose; UA, uric acid; T-C, total cholesterol; LDL-C, low-density lipoprotein cholesterol; HDL-C, high-density lipoprotein cholesterol; TG, triglycerides.

Table IV. Results of brachial artery reactivity testing.

\begin{tabular}{|c|c|c|c|}
\hline Parameter & Hypertensive $(n=75)$ & Normotensive $(n=65)$ & P-value \\
\hline \multicolumn{4}{|c|}{ BAD baseline (mm) } \\
\hline Mean \pm SD & $5.26 \pm 0.78$ & $4.95 \pm 0.66$ & \multirow[t]{2}{*}{0.01} \\
\hline Range & $3.40-7.20$ & $3.90-6.00$ & \\
\hline \multicolumn{4}{|c|}{ BAD hyperemic (mm) } \\
\hline Mean \pm SD & $5.53 \pm 0.83$ & $5.79 \pm 0.70$ & \multirow[t]{2}{*}{0.04} \\
\hline Range & $3.70-7.90$ & $4.70-7.13$ & \\
\hline \multicolumn{4}{|l|}{ FMD $(\%)$} \\
\hline Mean \pm SD & $5.22 \pm 4.58$ & $17.34 \pm 7.18$ & \multirow[t]{2}{*}{$<0.0001$} \\
\hline Range & $-4.26-18.14$ & $0-33.33$ & \\
\hline \multicolumn{4}{|c|}{ Flow baseline $(\mathrm{ml} / \mathrm{min})$} \\
\hline Mean \pm SD & $116 \pm 61$ & $106 \pm 49$ & \multirow[t]{2}{*}{0.30} \\
\hline Range & $36-295$ & $53-232$ & \\
\hline \multicolumn{4}{|c|}{ Flow hyperemic (ml/min) } \\
\hline Mean \pm SD & $792 \pm 314$ & $714 \pm 297$ & \multirow[t]{3}{*}{0.13} \\
\hline Range & $271-1498$ & $207-1489$ & \\
\hline P-value & $<0.0001$ & $<0.0001$ & \\
\hline \multicolumn{4}{|c|}{ Hyperemia (\%) } \\
\hline Mean \pm SD & $700 \pm 367$ & $638 \pm 315$ & \multirow[t]{2}{*}{0.28} \\
\hline Range & $114-2005$ & $46-1437$ & \\
\hline
\end{tabular}

BAD, brachial artery diameter; FMD, flow-mediated dilation. 
Table V. Prevalence of endothelial dysfunction at baseline.

\begin{tabular}{lcc}
\hline FMD response & $\begin{array}{c}\text { Hypertensive } \\
(\mathrm{n}=75)\end{array}$ & $\begin{array}{c}\text { Normotensive } \\
(\mathrm{n}=65)\end{array}$ \\
\hline Normal, $\mathrm{n}(\%)$ & $4(5.30)$ & $54(83.0)$ \\
Borderline, $\mathrm{n}(\%)$ & $14(18.60)$ & $4(6.1)$ \\
Moderately impaired, $\mathrm{n}(\%)$ & $32(42.60)$ & $2(3.0)$ \\
Severely impaired, $\mathrm{n}(\%)$ & $25(33.33)$ & $5 \quad(7.6)$ \\
\hline
\end{tabular}

Pearson $\chi^{2}=88.2, \mathrm{P}<0.0001$. FMD, flow-mediated dilation.

\section{Discussion}

To the best of our knowledge, the present study is the first report of allelic variation in the gene of the $p 22 P H O X$ component of the superoxide-generating enzyme, NADPH oxidase, in a community-based sample from Kashmir (India). We investigated the genotype and allele frequencies of the C242T polymorphism at the p22PHOX gene in 80 asymptomatic individuals from the community. Results indicate that in the selected population of hypertensive and normotensive Kashmiri individuals, the $p 22 \mathrm{PHOX}$ gene exhibits C242T polymorphism, with allele frequencies in Hardy-Weinberg equilibrium. In this study, 50, 45 and 5\% of individuals had the CC, CT and TT genotype, respectively. The frequency of the T-allele was $27.5 \%$ of the overall population. Genotype and gene frequencies were comparable between the hypertensive and the normotensive individuals. Additionally, the condition of Hardy-Weinberg equilibrium was satisfied in the subject groups and the overall study population, indicating the absence of genetic mutation, drift or selection for the locus in consideration. These data are also consistent with absence of gene flow (migration) as well as with the randomly-mating population characteristics of the Kashmir valley from where all the participants for the present study were drawn.

The distribution of C242T genotypes in this study is similar to that reported in several Caucasian populations. The T-allele frequency in our population (27\%) is slightly lower than that in Caucasians (median, 33\%) but higher than that in African-Americans (17\%), Han-Chinese living in Beijing (6.6\%) and Japanese living in Tokyo (7-13\%). The frequency of T-allele in non-Caucasian populations is generally lower. A study on a mixed US population (37) reported a T-allele frequency of $17 \%$ among African-Americans compared with $35 \%$ among Caucasians in a sample of 90 healthy adults.

Previous studies on the p22PHOX C242T polymorphism in Hispanics are more consistent with the results of the present study. In 210 healthy Spanish individuals from Madrid, the CC, CT and TT p22PHOX genotypes were present in 54, 44 and $2 \%$ participants, respectively, and the T-allele frequency was $23 \%$. A study of 119 healthy Venezuelans revealed the frequencies for CC, CT and TT genotypes to be 52.9, 40.3 and 6.8\%, respectively. The frequency of the T-allele in this Hispanic population was $27 \%$, the same as the T-allele frequency in the present study (45). The characteristics of participants, including gender distribution and anthropometric and renal function measurements were similar between the genotypes (TT, CT or CC) as well as with respect to the presence or absence of the T-allele. There was a trend towards lower T-C and lower TG levels in individuals with the T-allele compared with those without it, however, this was not identified to be statistically significant. Overall CHD risk was comparable between the genotypes and alleles. Results of the present study are consistent with several previous studies on the correlation between clinical phenotypes and $\mathrm{C} 242 \mathrm{~T}$ polymorphism at $p 22$ PHOX $(34,39,42,44,45,49,50)$. In a study conducted on 402 high-risk Finnish Caucasian patients undergoing coronary angiography, prevalence of CHD risk factors was not observed to be significantly different between individuals with different C242T genotypes or alleles (39). Additional studies have also largely reported no significant difference in CHD risk factors with respect to the p22PHOX C242T polymorphism $(34,42,44,45,50)$. Therefore, the overall body of evidence, including the present study, indicates no differential risk factor burden in individuals with or without the T-allele.

We did not observe BP levels or the prevalence of hypertension to be different between $\mathrm{C} 242 \mathrm{~T} p 22 \mathrm{PHOX}$ genotypes or in the presence or absence of the T-allele. Genotype frequencies were comparable between hypertensive and normotensive individuals and the frequency of the $\mathrm{T}$-allele was equal $(\mathrm{P}=0.50)$. Consistent with these results, the majority of previous studies have also found no association between p22PHOX C242T polymorphisms and BP level or the presence of hypertension $(34,39,42,45,50)$. By contrast, a case-control study (36) reported a significantly higher prevalence of CC genotype and $\mathrm{C}$ allele frequency in unrelated hypertensive Caucasians compared with normotensive counterparts. The causes for this discrepancy are not currently clear.

An important observation in the present study was the significantly lower fasting BG levels in individuals with the T-allele compared with individuals without this allele. In addition, the association between the T-allele and BG appeared to be dose-dependent with glucose levels lowest in TT, intermediate in $\mathrm{CT}$ and highest in the CC genotype ( $\mathrm{P}=0.018)$. Oxidative stress may be a factor in insulin resistance and it is possible that the $p 22 \mathrm{PHOX}$ C242T polymorphism effects plasma insulin levels by altering ROS production.

In the selected population of hypertensive and normotensive Kashmiri individuals, the $p 22 P H O X$ gene was identified to exhibit a $\mathrm{C} 242 \mathrm{~T}$ single nucleotide polymorphism, with allele frequencies in Hardy-Weinberg equilibrium. The genotype and allele distribution did not differ between hypertensive and normotensive individuals. There was no differential CV risk factor burden between different genotypes or alleles with the exception of significantly lower fasting BG level in individuals with the T-allele compared with those without the allele.

\section{References}

1. Zeiher AM, Drexler H, Wollschlager H, et al: Endothelial dysfunction of the coronary microvasculature is associated with coronary blood flow regulation in patients with early atherosclerosis. Circulation 84: 1984-1992, 1991.

2. Ross R: The pathogenesis of atherosclerosis: a perspective for the 1990s. Nature 362: 801-809, 1993

3. Davignon $\mathbf{J}$ and Ganz P: Role of endothelial dysfunction in atherosclerosis. Circulation 109: 27-32, 2004. 
4. Landmesser U, Horni B and Drexler H: Endothelial function. A critical determinant in atherosclerosis? Circulation 19: 27-33, 2004.

5. Ross R: Atherosclerosis - an inflammation disease. N Engl J Med 340: 115-125, 1999.

6. Altman R: Risk factors in coronary atherosclerosis athero-inflammation: the meeting point. Thrombosis J 1: 4-10, 2003.

7. Schächinger V and Zeiher AM: Atherogenesis - recent insights into basic mechanisms and their clinical impact. Nephrol Dial Transplant 17: 2055-2064, 2002.

8. Ohara Y, Peterson TE, Sayegh HS, et al: Dietary correction of hypercholesterolemia in the rabbit normalizes endothelial superoxide anion production. Circulation 92: 898-903, 1995.

9. Harrison DG: Cellular and molecular mechanisms of endothelial cell dysfunction. J Clin Invest 100: 2153-2157, 1997.

10. Brandes RP, Barton M,Philippens KM, et al: Endothelial-derived superoxide anions in pig coronary arteries: evidence from lucigenin chemiluminescence and historical techniques. J Physiol 500: 331-342, 1997.

11. Warnholtz A, Nickenig G, Schulz E, et al: Increased NADHoxidase-mediated superoxide production in the early stages of atherosclerosis: evidence for involvement of the rennin-angiotensin system. Circulation 99: 2027-2033, 1999.

12. Rajagopalan S, Kurz S, Münzel T, et al: Angiotensin II-mediated hypertension in the rat increases vascular superoxide production via membrane NADH/NADPH oxidase activation. J Clin Invest 97: 1916-1923, 1996.

13. Guzik TJ, West NEJ, Black E, et al: Vascular superoxide production by $\mathrm{NAD}(\mathrm{P}) \mathrm{H}$ oxidase association with endothelial dysfunction and clinical risk factors. Circ Res 86: 85-90, 2000.

14. Rueckschloss U, Galle J, Holtz J, et al: Induction of NAD(P) oxidase by oxidized low-density lipoprotein in human endothelia cells: antioxidative potential of hydroxymethylglutaryl coenzyme A reductase inhibitor therapy. Circulation 104: 1767-1772, 2001.

15. Sumimoto H, Hata K, Mizuki K, et al: Assembly and activation of the phagocyte NADPH oxidase. Specific interaction of the N-terminal Src homology 3 domain of p47PHOX with p22PHOX is required for activation of the NADPH oxidase. J Biol Chem 271: 22152-22158, 1996

16. Ushio-Fukai M, Zafari AM, Fukai T, et al: p22PHOX is a critical component of the superoxide generating NADH/NADPH oxidase system and regulates angiotensin II-induced hypertrophy in vascular smooth muscle cells. J Biol Chem 271: 23317-23321, 1996.

17. Sundaresan M, Yu ZX, Ferrans VJ, Irani K and Finkel T: Requirement for generation of $\mathrm{H}_{2} \mathrm{O}_{2}$ for platelet derived growth factor signal transduction. Science 270: 296-299, 1995.

18. Zalba G, Jose GS, Moreno MU, et al: NADPH oxidase mediated oxidative stress: genetic studies of p22PHOXgene in hypertension. Antioxid Redox Signal 7: 1327-1336, 2005.

19. Wyche KE, Wang SS, Griendling KK, et al: C242T CYBA polymorphism of NADPH oxidase is associated with reduced respiratory burst in human neutrophils. Hypertension 43: 1246-1251, 2004

20. Guzik TJ, West NE, Black DE, et al: Functional effects of the $\mathrm{C} 242 \mathrm{~T}$ polymorphism in the NAD $(\mathrm{P}) \mathrm{H}$ oxidase $\mathrm{p} 22 \mathrm{PHOX}$ gene on vascular superoxide production in atherosclerosis. Circulation 102: 1744-1747, 2000.

21. Laursen JB, Rajagopalan S, Galis Z, et al: Role of superoxide in angiotensin II induced but not catecholamine induced hypertension. Circulation 95: 588-593, 1997.

22. Mollnau H, Wendt M, Szocs K, et al: Effects of angiotensin II infusion on the expression and function of $\mathrm{NAD}(\mathrm{P}) \mathrm{H}$ oxidase and components of nitric oxide/cGMPsignaling. Circ Res 90: 58-65, 2002.

23. Fukui T, Ishizaka N, Rajagopalan S, et al: p22PHOX mRNA expression and NADPH oxidase activity are increased in aortas from hypertensive rats. Circ Res 80: 45-51, 1997.

24. Paravincini TM and Touyz RM: Redox signaling in hypertension. Cardiovasc Res 71: 247-258, 2006.

25. Suzuki H, Swei A, Zweifach BW, et al: In vivo evidence for microvascular oxidative stress in spontaneously hypertensive rats: hydroethidinemicrofluorography. Hypertension 25: 1083-1089, 1995.

26. Nakazono K, Watanabe N, Matsuno K, et al: Does superoxide underlie the pathogenesis of hypertension? Proc Natl Acad Sci USA 88: 10045-10085, 1991.

27. Higashi Y, Sasaki S, Nakagawa K, et al: Endothelial function and oxidative stress by products in human hypertension. Hypertension 41: 1096-1101, 2003

28. Redon J, Oliva MR, Tormos C, et al: Antioxidant activities and oxidative stress byproducts in human hypertension. Hypertension 41: 1091-1101, 2003.
29. Li L, Fink GD, Watts SW, et al: Endothelin I increases vascular superoxide via endothelin (A)-NAD(P)H oxidase pathway in low rennin hypertension. Circulation 107: 1053-1058, 2003.

30. Beswick RA, Dorrance AM, Leite R, et al: NADH/NADPH oxidase and enhanced superoxide production in the mineralocorticoid hypertensive rat. Hypertension 38: 1107-1111, 2001.

31. Pettit AI, Wong RK, Lee V, et al: Increased free radical production in hypertension due to increased expression of NADPH oxidase subunit p22PHOX in lymphoblast cell lines. J Hypertens 20 $677-683,2002$

32. Fortuno A, Olivan S, Beloqui O, et al: Association of increased phagocytic NAD $(\mathrm{P}) \mathrm{H}$ oxidase dependent superoxide production with diminished nitric oxide generation in essential hypertension. J Hypertens 22: 2169-2175, 2004

33. Zalba G, Beaumont FJ, San Jose G, et al: Vascular NADH/NADPH oxidase is involved in enhanced superoxide production in spontaneously hypertensive rats. Hypertension 35: 1055-1061, 2000.

34. Castejon AM, Bracero J, Hoffman IS, et al: NAD(P)H oxidase p22PHOXgene $\mathrm{C} 242 \mathrm{~T}$ polymorphism, nitric oxide production, salt sensitivity and cardiovascular risk factors in Hispanics. J Hum Hypertens 20: 772-779, 2006.

35. Nasti S, Balbi M, Fabbi P, et al: CYBA polymorphism associated with oxidative stress in Italian patients with early onset of coronary artery disease. Ital Heart J 3: S52-S54, 2002.

36. Moreno MU, Jose GS, Fortuno A, et al: The C242T CYBA polymorphism of NADPH oxidase is associated with essential hypertension. J Hypertens 24: 1299-1306, 2006.

37. Inoue N, Kawashima S, Kanazawa K, et al: Polymorphism of the NADH/NADPH oxidase p22PHOX gene in patients with coronary artery disease. Circulation 97: 135-137, 1998.

38. Fan M, Kähönen M, Rontu R, et al: The p22PHOX C242T gene polymorphism is associated with a reduced risk of angiographically verified coronary artery disease in a high-risk Finnish Caucasian population. The Finnish cardiovascular study. Am Heart J 152: 538-542, 2006.

39. Shimo-Nakanishi Y,Hasebe T, Suzuki A, et al: Functional effects of NAD $(\mathrm{P}) \mathrm{H}$ oxidase p22PHOX C242T mutation in human leukocytes and association with thrombotic cerebral infraction. Atherosclerosis 175: 109-115, 2004.

40. Ito D, Murata M, Watanabe K, et al: $\mathrm{C} 242 \mathrm{~T}$ polymorphism of NADPH oxidase p22PHOX gene and ischemic cerebrovascular disease in the Japanese population. Stroke 31: 936-939, 2000.

41. Cai H, Duarte N, Wilcken DE, et al: NADH/NADPH oxidase p22PHOX C242T polymorphism and coronary artery disease in the Australian population. Eur J Clin Invest 29: 744-748, 1999.

42. Cahilly C, Ballantyne CM, Lim DS, et al: A variant of p22PHOX, involved in generation of reactive oxygen species in the vessel wall, is associated with progression of coronary atherosclerosis. Circ Res 86: 391-395, 2000

43. Hyashi Okano R, Yamasaki Y, Kajimoto Y, et al: Association of $\mathrm{NAD}(\mathrm{P}) \mathrm{H}$ oxidase $\mathrm{p} 22 \mathrm{PHOX}$ gene variation with advanced carotid atherosclerosis in Japanese type 2 diabetes. Diabetes Care 26: 458-463, 2003.

44. Nasti S, Spallarossa P, Aitieri P, et al: C242T polymorphism in CYBA gene (p22phox) and risk of coronary artery disease in a population of Caucasian Italians. Dis Markers 22: 167-173, 2006.

45. Schachinger V, Britten MB, Dimmeler S, et al: NADH/NADPH oxidase p22PHOX gene polymorphism is associated with improved coronary endothelial vasodilator function. Eur Heart J 22: 96-101, 2001.

46. Schneider MP, Hilgers KF, Huang Y, et al: The C242T p22PHOX polymorphism and endothelium-dependent vasodilation in patients with hypercholesterolemia. Clin Sci 105: 97-103, 2003.

47. Li A, Prasad A, Mincemoyer R, et al: Relationship of the C242T p22PHOX gene polymorphism to angiographic coronary artery disease and endothelial function. Am J Med Genet 86: 57-61, 1999.

48. Levey AS, Bosch JP, Lewis JB, et al: A more accurate method to estimate glomerular filtration rate from serum creatinine: a new prediction equation. Modification of Diet in Renal Disease Study Group. Ann Intern Med 130: 461-470, 1999.

49. Inoguchi T, Li P, Umeda F, et al: High glucose level and free fatty acid stimulate reactive oxygen species production through protein kinase C-dependent activation of NADPH oxidase in cultured vascular cells. Diabetes 49: 1939-1945, 2000.

50. Hink U, Li H, Mollnau H, et al: Mechanisms underlying endothelial dysfunction in diabetes mellitus. Circ Res 88: E14-E22, 2001. 